\title{
Utilización del sector financiero para el lavado de dinero: perspectiva desde la legislación ecuatoriana ${ }^{1}$
}

\section{Use of the financial sector for money laundering: a perspective from the Ecuadorian legislation}

\author{
DOI: http://dx.doi.org/10.17981/juridcuc.14.1.2018.7
}

Artículo de investigación. Fecha de recepción: 23/05/2018 Fecha de aceptación: 10/09/2018

\author{
Mauricio De La Torre Lascano \\ Universidad Central del Ecuador (Ecuador) \\ cdelatorre@uce.edu.ec
}

Para citar este artículo:

De la Torre, M. (2018). Utilización del sector financiero para el lavado de dinero: perspectiva desde la legislación ecuatoriana. JURÍDICAS CUC, vol. 14, no. 1, pp. 145-166. DOI: http://dx.doi.org/10.17981/ juridcuc.14.1.2018.7

\section{Resumen}

El delito de lavado de activos es un problema social a nivel mundial que está presente en todos los sectores económicos donde se desarrollan las actividades financieras. Para determinar cuáles son los sectores financieros utilizados para llevar a cabo este delito se utilizaron varias fuentes bibliográficas, básicamente estudios realizados por organismos internacionales especializados en la materia, considerando la necesidad permanente de delimitación normativa. El objetivo de esta investigación fue determinar si existe una adecuada regulación normativa, sistematizando los respectivos sectores financieros en donde se desarrollan las actividades financieras. También se procedió al análisis de la reciente normativa emitida en Ecuador, obteniendo como resultado la responsabilidad penal de los funcionarios de los sujetos obligados cuando se omite el cumplimiento de sus obligaciones de control previstas legalmente. No obstante, los diferentes entes reguladores nacionales han emitido amplia, e inclusive, podría decirse excesiva normativa para cada uno de los sectores económicos.

Palabras clave: Lavado de activos, normativa ecuatoriana, sectores económicos, sujetos obligados

\section{Abstract}

The crime of money laundering is a social problem worldwide that is present in all economic sectors where financial activities take place. To determine which financial sectors are used to carry out this crime, several bibliographical sources were used, basically studies carried out by international organizations specialized on this subject. Mainly, the permanent need for regulatory delimitation was considered. The objective of this research was to determine if there is adequate regulation and systematization in the respective financial sectors where the financial activities are performed. In addition, the analysis of the recent regulations issued in Ecuador was conducted, obtaining as a result the criminal liability of the officials from the obligated parties to report when the fulfillment of their control obligations provided by law is omitted. However, the different national regulatory bodies have issued broad and even excessive regulation for each of the economic sectors.

Keywords: money laundering, Ecuadorian legislation, economic sectors, obligated parties

\footnotetext{
${ }^{1}$ Este trabajo forma parte de los resultados de la tesis doctoral denominada "Lavado de activos: estudio sobre la prevención (en especial referencia al caso ecuatoriano)" bajo la dirección del Dr. Eduardo Fabián Caparrós (Universidad de Salamanca).
}

The author; licensee Universidad de la Costa - CUC. 


\section{INTRODUCCIÓN}

El delito de lavado de activos está presente en todos los sectores económicos debido a que los perpetradores utilizan diversos y variados mecanismos ya sea para ocultar el origen ilegal de dichos fondos o poder disfrutar de las cuantiosas ganancias generadas. El profesor Eduardo Fabián Caparrós (1998) lo define como

el proceso tendiente a obtener la aplicación en actividades económicas lícitas, de una masa patrimonial derivada de cualquier género de conductas ilícitas, con independencia de cual sea la forma que esa masa adopte, mediante la progresiva concesión a la misma de una apariencia de legalidad (p. 76).

De manera que la definición incluye a organizaciones diferentes de las tradicionales instituciones financieras, estas personas naturales o jurídicas operan en distintos sectores productivos, comerciales o de servicios, ampliándose considerablemente el ámbito en donde puede presentarse este delito.

En el Ecuador son tres los sectores económicos claramente identificables: 1) financiero, 2) societario que incluye seguros y mercado de valores, y 3) economía popular y solidaria; cada sector tiene un ente regulador definido, que son: las Superintendencias de Bancos (SB), Superintendencias de Compañías, Valores y Seguros (SICVS), y Superintendencias de Economía Popular y Solidaria (SEPS), esta última creada en 2012. Lo particular es que cada organismo ha emitido normativa sobre lavado de activos para los denominados sujetos obligados. Debe entenderse como sujetos obligados aquellas personas naturales y jurídicas que tienen la obligatoriedad de informar a los entes reguladores a través de la entrega de los reportes previstos legalmente.

La precisión que debe realizarse es que esta vulneración es ejecutada por organizaciones criminales con conocimiento técnico suficiente para evadir la normativa o contar con la complicidad suficiente. Por ello, la corrupción suele contar con redes estables, con una estructura organizada que hace que el 
mercado negro de compraventa de actuaciones públicas funcione (Nieto, 2004).

Debido al auge del tráfico de drogas, que se convirtió en un verdadero problema de dimensiones gigantescas, se consideró necesaria la creación de un ente regulador a nivel mundial que emita normatividad que sea adoptada como estándar a nivel global. Con tal finalidad, se crea el Grupo de Acción Financiera Internacional (GAFI), que es un cuerpo intergubernamental establecido en 1989, cuyos objetivos son establecer normas y promover la aplicación efectiva de las medidas legales, reglamentarias y operativas para combatir el lavado de dinero, la financiación del terrorismo y otras amenazas relacionadas con la integridad del sistema financiero internacional (GAFI, 2018). Es lógico entender que las organizaciones criminales desarrollen esquemas para perpetrar el delito, conocidos como tipologías, que no son sino la explicación del proceso de lavado de activos utilizado por los delincuentes en el desarrollo de sus acciones. Estas tipologías pueden presentar diferentes modalidades de acuerdo con el contexto donde se realice y con los medios utilizados. Dentro de ese entorno, es lógico que aparezcan las denominadas señales de alerta que son elementos que permiten detectar en los sujetos obligados la posible presencia de operaciones de lavado de activos relacionadas con la tipología descrita (GAFILAT, 2008).

Los mecanismos y diversos artilugios que son utilizados por las organizaciones criminales con un alto contenido de ingeniería financiera incluyen vehículos corporativos, es decir, diferentes tipos de instrumentos financieros como los fideicomisos, que "además de oscurecer las identidades de los beneficiarios finales de un activo o el origen y destino de los fondos, estos vehículos corporativos también se usan a veces en los esquemas criminales como fuente de ingresos legales" (GAFI, 2007, p. 12).

El desarrollo de medidas fuertes y eficaces para proteger al sistema financiero contra el abuso solo es posible con el conocimiento de los métodos que los criminales, incluidos los terroristas, utilizan para generar y mover sus activos. A medida que los países aplican medidas más estrictas para prevenir el uso 
indebido del sistema financiero, los delincuentes deben buscar maneras diferentes de blanquear el producto de sus crímenes o transferir fondos para apoyar actividades terroristas (GAFI, 2016a). Por lo que esta investigación trata de explicar que este delito puede presentarse en todas las actividades financieras donde las personas naturales y jurídicas desarrollan sus actividades comerciales.

\section{Metodología}

El presente trabajo de investigación se desarrolló con base en una revisión documental que abarca el estudio y análisis bibliográfico sobre la diferente normativa emitida por organismos internacionales contra la lucha del lavado de activos debido al impacto global que tiene este delito sobre las naciones y la necesidad permanente de delimitación legal. Se utilizaron varias fuentes documentales, especialmente estudios realizados por organismos internacionales especializados en el tema, así como investigaciones académicas y doctrinales para determinar el estado del arte. Aunque existe vasto cúmulo de información sobre lavado de activos, se ha hecho énfasis sobre aquella que hace relación al esquema jurídico emitido en el Ecuador, ya que ello constituye la base del objetivo central de la investigación que determina la necesidad de regulación permanente como una obligatoriedad global y la exigencia de su aplicación inmediata debido a diferentes sucesos acaecidos que tienen como constante la actividad criminal. Es necesario acotar que, al tratarse de un estudio cualitativo documental, la técnica del análisis basado en la recopilación de doctrina y normativa internacional es el más idóneo.

\section{RESUlTAdOS Y DISCUSIÓN}

El objetivo general que buscó la investigación estuvo relacionado con la necesidad de una regulación permanente, como una obligatoriedad global, y la exigencia de su aplicación inmediata debido a diferentes acontecimientos acaecidos que tienen como constante la utilización de este delito; lo anterior, mediante 
la creación, adopción e implementación de una normativa que brinde seguridad jurídica para los denominados sujetos obligados en las diversas y múltiples actividades en el sector financiero en donde desarrollan sus actividades económicas, ante lo cual se procedió al siguiente análisis:

\section{1) Instituciones financieras (IFI)}

Tradicionalmente, ha sido el sector financiero y las instituciones financieras (IFI) las que han sido utilizadas, de manera premeditada o no, para ejecutar el proceso de lavado de activos o blanqueo de capitales debido básicamente a que su core de negocio radica en colocaciones y captaciones. Jindal (2008) señala que, a nivel mundial, los bancos se han convertido en un objetivo importante de las operaciones de lavado de dinero y los delitos financieros porque los bancos ofrecen una variedad de servicios e instrumentos que se pueden utilizar para ocultar la fuente de dinero. Marteau (2016) determina que

Los países tienen diversos marcos legales, administrativos y operacionales y diferentes sistemas financieros, por lo cual no pueden tomar todos medidas idénticas contra estas amenazas. Por lo tanto, las recomendaciones del GAFI fijan un estándar internacional que los países deberían implementar por medio de medidas adaptadas a sus circunstancias particulares ( $p$. 16).

Esta labor de evaluación debe ser permanente, incluyendo nuevos mecanismos de investigación criminal, así como de los aspectos reglamentarios y/o legales.

"Uno de los mecanismos aplicados por el GAFI que mayor efectividad ha demostrado en la configuración de las políticas antilavado de activos es la elaboración y revisión periódica de las listas que siguen la dinámica de actualización" (Goite y Medina, 2015, p. 55). Más, se debe tomar en consideración que pueden existir efectos colaterales en un país debido a la adopción de medidas rigurosas de control frente a este delito por las rápidas reacciones de los grupos criminales al cambiar de ubicación los fondos blanqueados, pues esto puede generar 
volatilidad en el sector financiero, amenazando la liquidez y la solvencia de las entidades financieras y dañar su reputación (Del Cid, 2013).

Sintura, Martínez y Quintana (2014) determinan que las legislaciones antilavado a nivel global han tomado como base la idea que para combatir este delito hay que detectarlo, y esta detección solo es posible si los intermediarios del mercado financiero informan a las autoridades sobre cualquier operación sospechosa. "Inicialmente, se obligaba a los bancos a conocer a sus clientes formalmente, y a reportar voluntariamente transacciones inusuales que pudieran estar relacionadas con el narcotráfico" (Jorge, 2012, p. 44). Las operaciones de las IFI están enfocadas a la intermediación financiera, requiriendo para desarrollar su accionar, inevitablemente, el uso de dinero físico en primera instancia por el ahorro de sus clientes, sin embargo, hoy en día utilizan diversos instrumentos, mecanismos y/o vehículos alternativos de medio de pago en línea con los avances tecnológicos, y es justamente por esta causa que el riesgo inherente de estas operaciones financieras determinan la necesidad de que existan directrices para prevenir el blanqueo de dinero proveniente de actividades ilícitas.

El GAFI (2012) define a las IFI como toda persona natural o jurídica que realiza como negocio las siguientes actividades $\mathrm{u}$ operaciones para o en nombre de un cliente, realizando el siguiente detalle:

1. Toma de depósitos y otros fondos reintegrables del público (incluyendo la banca privada);

2. préstamo [créditos personales, créditos hipotecarios, factoraje con o sin recurso y financiamiento de operaciones comerciales (incluyendo pérdidas)];

3. arrendamiento financiero o leasing (ello no abarca los acuerdos de arrendamiento financiero relacionado con los bienes de consumo);

4. transferencia de dinero o valores (no se aplica a las personas naturales o jurídicas que suministran a las instituciones financieras solamente mensajes u otro tipo de sistemas de apoyo para la transmisión de fondos); 
5. emisión y administración de medios de pago (ej.: tarjetas de crédito y débito, cheques, cheques de viajero, giros postales y giros bancarios, dinero electrónico);

6. garantías y compromisos financieros;

7. compraventa de: (a) instrumentos del mercado de dinero (cheques, letras, certificados de depósito, derivados, etc.); (b) moneda extranjera; (c) instrumentos de canje, tasas de interés e índices; (d) valores transferibles; y (e) negociación a futuro de productos primarios;

8. participación en emisiones de valores y prestación de servicios financieros relacionados con esas emisiones;

9. gestión de carteras individuales y colectivas;

10. custodia y administración de efectivo o valores líquidos en nombre de terceros;

11. otras formas de inversión, administración o gestión de fondos o de dinero en nombre de terceros;

12. suscripción y colocación de seguros de vida y otros seguros relacionados con la inversión, aplica tanto a las empresas de seguro como a los intermediarios de seguro (agentes y corredores);

13. cambio de moneda y divisas.

Advirtiendo la vulnerabilidad del sistema financiero global, el GAFI (2017) define que los servicios de transferencia de dinero o valores (Money or Value Transfer Services, MVTS, por sus siglas en inglés) juegan un papel importante en el sistema financiero internacional y en el apoyo a la inclusión financiera. El organismo también señala que, en diciembre de 2015, las Naciones Unidas estimaron que los países en desarrollo recibían más de 400 mil millones de dólares en remesas de migrantes que vivían en el extranjero en 2014. Sin embargo, al igual que otras instituciones financieras, los proveedores de MVTS también son vulnerables al abuso con fines de lavado de activos.

En el caso de Ecuador, la actividad financiera está definida en el Código Orgánico Monetario Financiero (COMF, 2014), que se encuentra en vigencia desde su publicación en el Segundo Suplemento del Registro Oficial No. 332 del 12 de septiembre del 2014, que estipula: 
actividad financiera es el conjunto de operaciones y servicios que se efectúan entre oferentes, demandantes y usuarios, para facilitar la circulación de dinero y realizar intermediación financiera; tienen entre sus finalidades preservar los depósitos y atender los requerimientos de financiamiento para la consecución de los objetivos de desarrollo del país. Las actividades financieras son un servicio de orden público, reguladas y controladas por el Estado, que pueden ser prestadas por las entidades que conforman el sistema financiero nacional, previa autorización de los organismos de control, en el marco de la normativa que expida la Junta de Política y Regulación Monetaria y Financiera (artículo 143).

Se puede decir que la relación del proceso del lavado de dinero con las IFI es muy estrecha e íntima por la posesión de grandes cantidades de efectivo por parte de los delincuentes que requieren insertarlos en el mercado formal. Ejemplificando este vínculo, Grosse (2001) señala que, debido a los cheques, tarjetas de crédito y otros medios no monetarios son comúnmente aceptados en transacciones financieras legítimas en la sociedad de hoy, llevar a cabo una transacción en efectivo voluminosa puede llamar la atención indeseable a los criminales que desean utilizar su dinero adquirido ilegalmente.

En consecuencia, el perpetrador empleará a un tercero para colocar los fondos de origen ilícito en el sistema financiero para que éstos pasen desapercibidos, o para transportar físicamente el efectivo fuera del país de origen, pero en la actualidad este proceso ya no requiere ni transportar físicamente el dinero a otra jurisdicción, ni tampoco utilizar otra IFI. Fabián, Prado, Blanco y Zaragoza (2014) determinan que

Una de las formas más discretas de canalizar dinero de un punto a otro consiste en valerse de mecanismos de compensación entre dos oficinas de una misma institución financiera, estén o no ubicadas bajo una misma jurisdicción. En estos casos, los dispositivos oficiales de detección de operaciones sospechosas suelen revelarse ineficaces, toda vez que estos movimientos se verifican puertas adentro de una misma entidad, generalmente ajenos a los controles que pudieran proceder del exterior de la misma (p. 80). 
La internacionalización de transacciones financieras como resultado de la globalización y la búsqueda de rentabilidad inmediata por parte de las IFI son factores que contribuyen al proceso de lavado. Martínez (2015) anota que

Este sistema económico orientado a la máxima rentabilidad por encima de cualquier otra ética, es fácil entender que no ponga ningún impedimento a la entrada de flujos de dinero con indiferencia de su procedencia. En este proceso de integración de los beneficios de los bienes y servicios ilegales juegan de forma prioritaria dos elementos, el primero: la lógica del sistema que está orientado a crecer y generar beneficios por encima de todo, y segundo: las puertas traseras que tiene el sistema para introducir todo el flujo de dinero sin importar la procedencia, estas puertas son los paraísos fiscales. Esto permite la integración de los beneficios de la económica ilegal en la economía legal. Generando así una economía criminal paralela dentro del sistema económico global (p. 339).

Destacando la incongruencia de esa interacción entre los flujos de dinero del blanqueo de capitales, mercados financieros internacionales y las fases del proceso de blanqueo, Alasmari (2012) aporta que debido a que los narcotraficantes casi siempre utilizan dinero en efectivo como medio de pago, y porque la mayoría de las transacciones financieras legítimas en el mundo informático actual de los sistemas financieros globales no lo hacen, existe una disyunción inherente entre la forma que toma el dinero del perpetrador y la forma que necesitaría tomar para ser vista como legítima, o por lo menos no ser marcada inmediatamente como muy probablemente ilegítima. "Inclusive si la industria financiera no ha violado ninguna ley, facilita el delito subyacente, ya sea el tráfico ilegal de drogas o el soborno, permitiendo a las personas establecer empresas o abrir cuentas sin identificación de los propietarios" (Rose-Ackerman y Palifka, 2017, p. 86).

Debido a este problema y porque esta etapa marca el momento en el cual el delincuente y el dinero están más estrechamente vinculados y más fácilmente conectables, sería en la primera fase del proceso, denominada colocación, la etapa de lavado de dinero en la que resultaría más fácil detectar las operaciones de blanqueo 
por las IFI (Gálvez, 2014), y posteriormente, por los organismos o instituciones encargadas de hacer cumplir la ley.

El uso del dinero en efectivo, o cash, es cada vez menor, justamente por los avances tecnológicos y las variadas alternativas que ofrecen en este sector las organizaciones a sus usuarios que cada vez más hacen todo online o en línea. Fabián (1998) refiere que

El enorme desarrollo de los intercambios económicos experimentado en nuestra sociedad ha demostrado las grandes limitaciones a las que se encuentra sujeto el dinero corriente como medio de saldar las obligaciones. La necesidad de contar con nuevos instrumentos al servicio de ese complejo mercado ha hecho que el pago en metálico haya sido relegado a un segundo plano en favor de otros muchos medios, más ágiles y seguros, propiciados por los avances jurídicos y tecnológicos (p. 110).

A su vez, refiriéndose a la Banca online y métodos modernos de pago, Blanco (2015) señala que la gran mayoría de las IFI permiten a sus clientes operar a través de internet. Es más, existen incluso entidades totalmente virtuales que no mantienen oficinas para atender al público. A través de estas cuentas y sin necesidad de acudir presencialmente al banco, se pueden realizar operaciones, algunas de las cuales pueden ser constitutivas de lavado de activos.

Se debe tomar en consideración que dentro de cada país debe existir un supervisor bancario que, en resumidas cuentas, es el responsable de la seguridad y solvencia del sistema financiero. Entre las principales competencias que tienen que realizar los entes supervisores que el Comité de Supervisión Bancaria de Basilea (2012) ha determinado, constan:

(i) la protección de los depositantes, algo estrechamente relacionado con la seguridad y la solidez, y con la constitución y operación de sistemas eficaces de garantía de depósitos; (ii) la estabilidad financiera, habitualmente muy ligada también a la solvencia del sector bancario; (iii) la defensa de los consumidores, un área en la que perjuicios, demandas y riesgo de reputación pueden perjudicar a la seguridad y solidez, o (iv) la inclusión financiera, donde debe tenerse cuidado para evitar efectos nocivos sobre la seguridad y la solvencia (p. 5). 
Tantas y variadas son las técnicas utilizadas para eludir los controles establecidos por las normas de prevención en las IFI que en muchas ocasiones cuentan con la complicidad de sus funcionarios. Una de las técnicas más comunes radica en el "fraccionamiento de las sumas elevadas de dinero en otras múltiples de menor cuantía a lo largo de un período determinado, bien sea al contado, bien a través de otros instrumentos" (Bermejo, 2009 , p. 129), este procedimiento es conocido como smurfing o pitufeo. Con ello nace la necesidad de establecer reportes cuando la cuantía de las operaciones sea superior a un determinado valor, estos límites son conocidos como umbrales. En Ecuador, la Ley orgánica de prevención, detección y erradicación del delito de lavado de activos y del financiamiento de delitos, emitida el 21 de julio (2016), en el artículo 4, literal c) determina

c) Registrar las operaciones y transacciones cuya cuantía sea igual o superior a diez mil dólares de los Estados Unidos de América o su equivalente en otras monedas, así como las operaciones y transacciones múltiples que, en conjunto, sean iguales o superiores a dicho valor, cuando sean realizadas en beneficio de una misma persona y dentro de un período de treinta días (Artículo 4).

En Europa, la reciente Directiva 2018/843 (Parlamento Europeo, 2018) en línea con las Directivas anteriores, exige que los sujetos obligados apliquen medidas de debida diligencia a sus clientes en tanto se vaya a establecer un nexo permanente u ocasional de negocios, como en el caso de personas que negocien con bienes, cuando efectúen transacciones ocasionales en efectivo por un importe igual o superior a diez mil euros, entre otras circunstancias. Recomendando inclusive a los Estados miembros puedan fijar umbrales menores, establecer otras limitaciones generales a la utilización de efectivo y adoptar disposiciones más estrictas.

Por tanto, las IFI deben cumplir con exigencias normativas para evitar que adicionalmente se utilicen personas naturales o jurídicas ficticias como testaferros o empresas fantasma, respectivamente, con la finalidad de encubrir la titularidad real y origen de los fondos o bienes ilícitos. 
Un estudio realizado por el Departamento del Tesoro de Estados Unidos (2015) determina que las vulnerabilidades subyacentes de lavado de dinero siguen siendo en gran parte las mismas que las identificadas en 2005. Los métodos de lavado de dinero identificados en esa evaluación indican las siguientes vulnerabilidades:

- Uso de efectivo e instrumentos monetarios en montos bajo los umbrales regulatorios de mantenimiento de registros e informes;

- apertura de cuentas bancarias y de corretaje utilizando testaferros para disfrazar la identidad de las personas que controlan las cuentas;

- crear entidades jurídicas sin información exacta sobre la identidad del beneficiario del efectivo;

- uso indebido de productos y servicios como resultado del cumplimiento deficiente de las obligaciones contra el lavado de dinero; $y$

- comerciantes e instituciones financieras que faciliten la actividad ilícita.

Existe una íntima relación del sector financiero con el delito de lavado de activos, y, a manera de conclusión, Fabián, Prado, Blanco y Zaragoza (2014) señalan que

La inversión en el sector financiero y el dominio de la gestión de la actividad crediticia constituyen objetivos dotados de un poderoso atractivo. La posibilidad de servir de cauce de inmensas fortunas hace que estas empresas se encuentren, sin lugar a dudas, entre las más codiciadas por las organizaciones dedicadas al reciclaje. Por otra parte, conviene tener presente que el sistema bancario es, además, el principal receptor de la documentación relativa a toda clase de intercambios comerciales, ofreciendo con ello la posibilidad de manipular tales registros según convenga (p. 88).

\section{2) Establecimientos financieros no convencionales}

Al ser el sector financiero el más utilizado para perpetrar el delito de blanqueo, naturalmente la normativa preventiva se centró en la banca, seguros y sociedades de bolsa, lo que produjo un 
desplazamiento de la actividad delictiva a otros establecimientos financieros dado que su operatividad se encontraba menos regulada. Dentro de este grupo, Bermejo (2009) señala a las oficinas de cambio de moneda como entidades que poseen unas cualidades excelentes para el suministro irregular de divisas. Debido a la informalidad que ha caracterizado a este tipo de negocios, se ha convertido en un factor clave que ha servido de base para las redes que se dedican a lavar dinero a gran escala. Dependiendo del nivel a blanquear, puede requerirse la utilización de personas que prestan sus nombres para realizar los cambios de moneda y viajan al exterior, o inclusive, la apertura de una casa de cambio si son grandes los volúmenes a lavar.

Otro mecanismo utilizado es el contrabando de dinero en efectivo, es decir, sacar al exterior ingentes cantidades de dinero mediante la utilización de varias técnicas, como por ejemplo, compañías aéreas de correos internacionales, compañías aéreas de pasajeros, aviones o vehículos privados, transporte de carga, o simplemente llevarlo consigo, toda vez que no dejan rastro. En Ecuador existe el Impuesto a la Salida de Divisas, también denominado ISD y asciende al $5 \%$.

El hechogenerador deesteimpuestoloconstituyela transferencia, envío o traslado de divisas que se efectúen al exterior, sea en efectivo o a través del giro de cheques, transferencias, retiros o pagos de cualquier naturaleza, inclusive compensaciones internacionales, sea que dicha operación se realice o no con la intervención de las instituciones que integran el sistema financiero (Servicio de Rentas Internas-SRI, 2018).

Adicionalmente, lo pagan las personas que salgan del país llevando consigo más de tres salarios básicos unificados (USD 1.158). Es necesario acotar que el Ecuador tiene establecido el dólar como moneda oficial, por tanto, la fuga de dólares hacia países vecinos con moneda más débil incrementa aún más estos mecanismos. "Se trata de un método muy común, poco sofisticado, barato y relativamente bajo en riesgos. Como consecuencia de la globalización del mercado, y del aumento del volumen comercial mundial, es prácticamente imposible examinar todos los cargamentos que cruzan las fronteras" (Blanco, 2015, p. 81). 
Dentro de esta clasificación, el GAFI (2012) también señala

Servicios de transferencia de dinero o valores (STDV) se refiere a los servicios financieros que involucran la aceptación de efectivo, cheques, otros instrumentos monetarios $u$ otros depósitos de valor y el pago de una suma equivalente en efectivo $\mathrm{u}$ otra forma a un beneficiario mediante una comunicación, mensaje, transferencia o a través de una red de liquidación a la que pertenece el proveedor de MVTS. Las transacciones efectuadas por estos servicios pueden involucrar uno o más intermediarios y un pago final a un tercero, y pueden incluir cualquier método nuevo de pago (p. 129).

García, López y Mallada (2015) señalan que a veces estos servicios tienen lazos con regiones geográficas en particular y se describen usando una serie de términos específicos, incluyendo hawala, [hundi] y [fei-chen].

La internacionalización de transacciones económicas es cada vez más asidua y el combate contra el lavado de activos ha sido considerado una prioridad mundial; por estas razones, refiriéndose a los servicios de transferencias de dinero o valores, el GAFI (2016b) determina que los proveedores de MVTS deben consultar diversas fuentes de información para identificar, gestionar y mitigar estos riesgos. Esto incluye tener en cuenta las tipologías, indicadores de riesgo, banderas rojas, orientaciones y/o guías emitidos por las autoridades nacionales competentes y el GAFI. Incluyendo normatividad propia que esté en línea con los preceptos o directrices emitidas.

\section{Conclusiones}

Fruto de las diferentes y cada vez más variadas actividades ilícitas cometidas tanto en el sector público como en el sector privado, los delincuentes consiguen descomunales ganancias, mismas que deben ser insertadas en los flujos de la economía legal para darles apariencia legítima y poder disfrutar de ellas, por lo que existe una relación intrínseca entre el delito de lavado de activos con las IFI en primera instancia y con los sectores productivos y económicos donde las personas naturales y jurí- 
dicas desarrollan sus actividades comerciales, toda vez que es obligatorio el uso del sistema financiero para poder desarrollar sus actividades operacionales, las cuales pueden ser utilizadas a manera de pantalla para conseguir su cometido de lavar dichas colosales ganancias.

Esta actividad no es para nada reciente, por lo que diferentes organismos internacionales han emitido estándares internacionales que deben ser adoptados por las naciones a nivel mundial. Existe un alto grado de homogeneización en las legislaciones contra el lavado de activos en el mundo (Etcheberry, 2015). "El cumplimiento normativo coexiste en el entorno empresarial como una exigencia regulatoria ante un escenario totalmente cambiante e incierto al que se enfrentan las organizaciones en la actualidad, escenarios que no siempre son de fácil identificación" (De La Torre, 2017, p. 122). En el Ecuador, con fecha 21 de julio (2016), mediante 2do. Suplemento Registro Oficial $\mathrm{N}^{0} 802$, se emitió la Ley orgánica de prevención, detección y erradicación del delito de lavado de activos y del financiamiento de delitos, que entre otras cosas incluye la obligatoriedad de reportar las transacciones económicas sospechosas realizadas por personas naturales o jurídicas que no guarden correspondencia con el perfil económico o financiero; previamente se reportaba únicamente las transacciones económicas inusuales o injustificadas. Asimismo, incrementa, la obligatoriedad de informar a la Unidad de Análisis Financiero y Económico (UAFE), no solamente los sujetos obligados sino todo ciudadano que conociera de actividades que pudieran constituir operaciones inusuales, injustificadas o sospechosas (artículo 7). El Código Orgánico Integral Penal (COIP, 2014) determina responsabilidad penal de los funcionarios de un sujeto obligado a reportar cuyo deber incluya expresamente funciones de prevención, detección y control de lavado de activos, omitiendo el cumplimiento de sus obligaciones de control previstas legalmente (artículo 319). El delito corporativo acentúa el hecho de que la infracción se ha cometido en el interior de una organización, y que puede tener por ello algún tipo de responsabilidad de carácter civil, administrativa o penal (Nieto, 2014). 
Adicionalmente, si bien se amplía el rango de sujetos obligados a reportar a la UAFE, en los que se incluye a los promotores artísticos y organizadores de rifas, están pendientes de ser incluidos muchos sujetos obligados de diferentes sectores económicos, siendo el sector deportes una clara muestra de lo aseverado.

Resulta necesario destacar lo contradictorio y paradójico de la reciente normativa de orden preventivo expedida para el sector financiero ecuatoriano, toda vez que a pesar de haberse emitido nuevos cuerpos legales y derogado muchas codificaciones, tal como lo señala la Resolución No. 385-2017-A emitida por la Junta de Política y Regulación Monetaria y Financiera (JPRMF), publicada en el 2do. Suplemento Registro Oficial No. 22 de fecha 26 de junio (2017), en el Libro I: Sistema Monetario y Financiero, se omite al sector financiero propiamente dicho, lo que da lugar a dos condiciones que deben ser contempladas, adoptadas, modificadas e implementadas con el carácter de urgente en el sistema nacional ecuatoriano de prevención para que éste funcione adecuadamente:

i. obviamente, se tendrá que emitir una nueva modificación, regularización, actualización y/o cambio a la reciente normativa que incluya al sector financiero dentro del Libro I: Sistema Monetario y Financiero;

ii. se encuentra vigente la normativa anterior que la resolución ha derogado, en tanto se emita el nuevo cuerpo legal.

La aplicación de ingeniosos esquemas de ingeniería financiera totalmente vanguardistas a los entes reguladores para perpetrar este delito que lacera la sociedad y corroe el Estado de Derecho, afectando a los protagonistas en los sectores económicos, determina la necesidad de regulación permanente como una obligatoriedad global y la exigencia de su aplicación inmediata. Actualmente, las instituciones financieras, especialmente, y el resto de sujetos obligados deben contar con mecanismos, controles y procedimientos internos que prevengan, identifiquen y, en ciertos casos, hagan que indicios o evidencias concretas de tales crímenes sean reportados a las autoridades 
(Pinheiro, Mello y da Conceição, 2017). El régimen antilavado de activos ha inducido a los bancos a tomar en serio su obligación de evitar contacto directo con dinero proveniente de actividades ilícitas mediante el establecimiento y desarrollo de sistemas de información y técnicas de monitoreo que los hacen menos activos para el cometimiento del delito (Reuter y Truman, 2004). Por tanto, el cumplimiento normativo preventivo, por un lado, así como la actualización permanente de la legislación nacional en línea con preceptos internacionales, constituye no solo una obligación normativa, sino que conlleva de manera inherente estándares de ética, responsabilidad y compromiso para mermar la continua y permanente irrupción de este mal que devasta a las naciones.

\section{REFERENCIAS}

Alasmari, K. (2012). Cleaning up Dirty Money: The Illegal Narcotics Trade and Money Laundering. Economics \& Sociology, 5(2a), 139-148. Recuperado de http://www.economics-sociology.eu/files/15_MOD_Dirty\%20Money_e\%20new.pdf

Bermejo, M. (2009). Prevención y castigo del blanqueo de capitales. Una aproximación desde el análisis económico del Derecho. [Tesis doctoral]. Universitat Pompeu Fabra, España. Recuperado de http://www.tdx.cat/TDX-0223110-120851

Blanco, I. (2015). El delito de blanqueo de capitales. Navarra: Aranzadi.

Comité de Supervisión Bancaria de Basilea. (2012). Principios básicos para una supervisión bancaria eficaz. Basilea: Banco de Pagos Internacionales. Recuperado de http://www.bis.org/ publ/bcbs213_es.pdf

De La Torre, M. (2017). Responsabilidad Social Corporativa y Auditoría Interna, una exigencia global imperativa. Revista Metanoia, 3(3), 213-226.

Del Cid, J. (2013). Detección del blanqueo y sus efectos socioeconómicos. En, M. Abel Souto y N. Sánchez (Coords.), III Congreso sobre prevención y represión del blanqueo de dinero (43-61). Valencia: Tirant Lo Blanch. 
Departamento del Tesoro de Estados Unidos. (2015). National Money Laundering Risk Assessment 2015. Washington D.C.: Department of the Treasury. Recuperado de: https://www. treasury.gov/resource-center/terrorist-illicit-finance/Documents/National\%20Money\%20Laundering\%20Risk\%20Assessment\%20\%E2\%80\%93\%2006-12-2015.pdf

Etcheberry, W. (2015). La regulación internacional del lavado de activos y el financiamiento del terrorismo. En K. Ambos, C. Caro y E. Malarino (Coords.), Lavado de activos y compliance. Perspectiva internacional y derecho comparado (pp. 91-142). Lima: Jurista Editores.

Fabián, E. A. (1998). El delito de blanqueo de capitales. Madrid: Editorial Colex.

Fabián, E., Prado, V., Blanco, I., Zaragoza, J. (2014). Combate al lavado de activos desde el sistema judicial. Edición Especial para el Perú. Washington, DC: CICAD. Recuperado de http:// www.cicad.oas.org/Lavado_Activos/esp/Documentos/OEA\%20 CICAD\%20LIBRO\%204\%20EDICION.pdf

GAFI. (2007). Money Laundering and Terrorist Financing Through the Real Estate Sector. París: GAFI. Recuperado de http://www. fatf-gafi.org/media/fatf/documents/reports/ML\%20and\%20 TF\%20through\%20the\%20Real\%20Estate\%20Sector.pdf

GAFI. (2012). Estándares internacionales sobre la lucha contra el lavado de activos y el financiamiento del terrorismo y la proliferación. Las recomendaciones del GAFI. París: GAFI. Recuperado de http://www.fatf-gafi.org/media/fatf/documents/ recommendations/pdfs/FATF-40-Rec-2012-Spanish.pdf

GAFI. (2016a). Annual report 2014-2015. París: GAFI. Recuperado de http://www.fatf-gafi.org/publications/fatfgeneral/documents/annual-report-2014-2015.html

GAFI. (2016b). Guidance for a Risk-Based Approach for Money or Value Transfer Services. París: GAFI. Recuperado de http:// www.fatf-gafi.org/media/fatf/documents/reports/GuidanceRBA-money-value-transfer-services.pdf

GAFI. (2017). Money or Value Transfer Services. París: GAFI. Recuperado de http://www.fatf-gafi.org/publications/fatfrecommendations/documents/rba-money-or-value-transfer.html 
GAFI. (10 de mayo de 2018). Who we are. Recuperado de http:// www.fatf-gafi.org/about/whoweare/

GAFILAT. (2008). Tipologías regionales GAFISUD-2008. Quito: GAFILAT. Recuperado de http://pplaft.cnbs.gob.hn/wp-content/uploads/2015/05/Tipolog\%C3\%ADas-Regionales-GAFISUD-2008.pdf

Gálvez, R. (2014). Los modus operandi en las operaciones de blanqueo de capitales. Barcelona: Bosch.

García, C., López, F. y Mallada, C. (2015). Guía práctica de prevención del blanqueo de capitales. Pamplona: Aranzadi.

Goite, M. y Medina, A. (2015). El delito de lavado de activos: necesario análisis desde una dimensión plural. En, G. Armienta, M. Goite, A. Medina, L. Gambino y L. García (Coords.), El lavado de dinero en el siglo XXI. Una visión desde los instrumentos jurídicos internacionales la doctrina y las leyes en América Latina y España (21-66). Sinaloa: Unijuris.

Grosse, R. (2001). Drugs and money: Laundering Latin America's cocaine dollars. Londres: Praeger.

Jindal, K. (2008). Anti-Money laundering on Banks. En K. Chandrasekharan y A. Francis (Eds.), Prevention of Money Laundering - Legal and Financial Issues (89-97). Nueva Delhi: The Indian Law Institute.

Jorge, G. (2012). Políticas de control del lavado de dinero. En, H. Bertazza y F. D’Albora (Dirs.), Tomo I Tratado de lavado de activos y financiación del terrorismo: Prevención, investigación y represión (43-104). Buenos Aires: La Ley.

Marteau, J. (2016). Criminalización del lavado de activos. Consideraciones político-criminales sobre la efectividad. Buenos Aires: Konrad Adenauer Stiftung.

Martínez, J. (2015). Estrategias multidisciplinarias de seguridad para prevenir el crimen organizado. [Tesis doctoral]. Universidad de Barcelona, España. Recuperado de http://hdl.handle. net/10803/298308

Nieto, A. (2004). La corrupción en las transacciones comerciales internacionales. En, A. Nieto (Coord.), Estudios de Derecho Penal (45-151). Ciudad Real: Universidad de Castilla la Mancha. 
Nieto, A. (2014). El cumplimiento normativo. En, Tirant Lo Blanch (Ed.), Manual de cumplimiento normativo y responsabilidad penal de las personas jurídicas (25-48). Valencia: Tirant Lo Blanch.

Pinheiro, T., Mello, L. y da Conceição, P. (2017). Compliance integrado em instituições financeiras: prevenção à lavagem de dinheiro e anticorrupção. En, R. Schermann (Coord.), Bancos e Serviços financeiros: visões atuais (141-161). Sao Paulo: Blucher.

República del Ecuador. Junta de Política y Regulación Monetaria y Financiera. (26 de junio de 2017). Apruébese la Codificación de resoluciones monetarias, financieras, de valores y seguros. [Resolución No. 385-2017-A]. 2do. suplemento registro oficial No. 22. Recuperado de https://www.derechoecuador.com/files/images/Documentos/R.\%20O.\%20(2SP)\%20junio\%2026\%20No.\%2022-2017.pdf

República del Ecuador. Asamblea Nacional. (21 de julio de 2016). Ley orgánica de prevención, detección y erradicación del delito de lavado de activos y del financiamiento de delitos. [Oficio No. SAN-2016-1308]. 2do. Suplemento Registro Oficial No. 802. Recuperado de https://www.fides.ec/wp-content/ uploads/2016/07/R.O.-802-2s-julio-21-2016.pdf

República del Ecuador. Asamblea Nacional. (12 de septiembre de 2014). Código Orgánico Monetario Financiero. COMF. [Oficio No. SAN-2014-1305]. Registro Oficial No. 332. Recuperado de http://www.pge.gob.ec/documents/Transparencia/ antilavado/REGISTROOFICIAL332.pdf

República del Ecuador. Asamblea Nacional. (10 de febrero de 2014). Código Orgánico Integral Penal. COIP. [Oficio No. SAN-20140138]. Suplemento Registro Oficial No. 180. Recuperado de https://tbinternet.ohchr.org/Treaties/CEDAW/Shared\%20 Documents/ECU/INT_CEDAW_ARL_ECU_18950_S.pdf

Reuter, P. y Truman, E. (2004). Chasing Dirty Money: The Fight Against Money Laundering. Washington, D.C.: Peterson Institute. 
Rose-Ackerman, S. y Palifka, B. (2017). Corruption, Organized Crime, and Money Laundering. En K. Basu y T. Cordella (Eds.), Institutions, Governance and the Control of Corruption (75-111). Washington, D.C.: Palgrave Macmillan.

Servicio de Rentas Internas-SRI. (2018). Impuesto a la Salida de Divisas (ISD). Recuperado de: www.sri.gob.ec/web/guest/ impuesto-a-la-salida-de-divisas-isd

Sintura, F., Martínez, W. y Quintana, F. (2014). Sistemas de prevención de lavado de activos y de financiación del terrorismo. Bogotá, D.C.: Legis.

Unión Europea. Parlamento Europeo. (2018). Por la que se modifica la Directiva (UE) 2015/849 relativa a la prevención de la utilización del sistema financiero para el blanqueo de capitales o la financiación del terrorismo, y por la que se modifican las Directivas 2009/138/CE y 2013/36/UE. [Document 32018L0843]. Diario Oficial de la Unión Europea, L 156. Recuperado de https://eur-lex.europa.eu/legal-content/ES/ TXT/?uri=CELEX\%3A32018L0843 
Mauricio De La Torre Lascano es Doctor por la Universidad de Salamanca (becario) dentro del programa doctoral "Estado de Derecho y Gobernanza Global”. Magíster en Gerencia Empresarial, MBA, por la Escuela Politécnica Nacional. Diploma superior en docencia universitaria y auditor por la Universidad Central del Ecuador. Docente titular e investigador en dicha universidad. Autor de artículos y trabajos en congresos internacionales en las líneas de investigación: lavado de activos y corrupción. Becario del gobierno francés para el Ciclo Internacional sobre Administración Pública (CISAP) "Fighting Corruption", Escuela Nacional de Administración (ENA), Francia. 